\title{
Fältexperiment för att studera etnisk diskriminering på den svenska arbets- och bostadsmarknaden
}

\author{
ALI M. AHMED \& JAN EKBERG
}

Under senare år har fältexperiment använts för att studera etnisk diskriminering på den svenska arbets- och bostadsmarknaden. I nedanstående framställning ges en presentation av fältexperiment som metod och en översikt

över den forskning som genomförts med hjälp av fältexperiment i Sverige. Dessutom görs en framåtblickande diskussion.

\section{Inledning}

Problematiken kring bostadssegregationen och den svaga arbetsmarknaden för invandrare har ofta varit i fokus bland såväl politiker som forskare. Det föreligger dessutom en samstämmighet att svårigheter för invandrare på arbets- och bostadsmarkna-

Ali M Ahmed, docent i nationalekonomi, Centrum för arbetsmarknadspolitisk forskning (CAFO), Växjö universitet

Jan Ekberg, professor i nationalekonomi, Centrum för arbetsmarknadspolitisk forskning (CAFO), Växjö universitet den till en inte oväsentlig del kan vara orsakade av etnisk diskriminering. Med etnisk diskriminering avses olikbehandling av personer med utländsk bakgrund trots att de har likvärdiga egenskaper som infödda. På arbetsmarknaden innebär det t.ex. att arbetsgivare väljer att ge arbete åt infödda i första hand, trots att personer med utländsk bakgrund är minst lika kvalificerade och produktiva som infödda. På bostadsmarknaden kan det t.ex. innebära att personer med utländsk bakgrund väljs bort, trots att de är lika skötsamma och kreditvärdiga som infödda. Diskriminering kan ta sig olika 
uttryck och det är oftast svårt att mäta och fastställa förekomsten av diskriminering (För en fördjupad diskussion om problematiken kring att mäta och säkerställa diskriminering se Nekby 2006).

Empiriska studier om diskriminering har i huvudsak använt fem metoder. En metod är att använda enkätundersökningar eller intervjuer. Ansatsen har sina fördelar i att den metodmässigt är relativt enkel men det finns också nackdelar. Det finns två varianter. En är att helt enkelt fråga individer om de anser sig ha blivit diskriminerade (se t.ex. Lange 2000). Nackdelen med denna variant är att en individ kan anse sig som diskriminerad även om så inte har varit fallet. Vidare kan en individ ha blivit diskriminerad men att denne inte vet om att diskriminering har förekommit. En annan variant är att kartlägga förekomst av negativa attityder bland infödda mot invandrare eller andra grupper i samhället (se t.ex. Arai et al. 1999). Men frågan är vad attityder säger om faktiskt diskrimineringsbeteende. En klassisk studie av LaPiere (1934) visar att attityder inte behöver prediktera beteende. Det finns numera ett mycket stort antal studier i många länder där diskriminering undersökts med hjälp av enkätundersökningar eller intervjuer (se t.ex. Mayda 2006, Walker 1994, Sheridan 2006 och Zick et al. 2002).

En annan metod är regressionsmetoden. Exempelvis jämförs invandrare och infödda med avseende på löner och arbetslöshet samtidigt som det i en ekonometrisk modell standardiseras för skillnader i ålder, kön, civilstånd, utbildning, arbetslivserfarenhet etc. mellan grupperna. Om det ändå finns skillnader i löner och arbetslöshet mellan grupperna så tolkas detta som indikationer på diskriminering. Fördelen med denna metod är att registerdata (åtminstone vad gäller Sverige och några andra länder) kan användas med ett mycket stort antal individer och observationer. Nackdelen är att det kan finnas andra och ickeobserverbara skillnader mellan individerna i de båda grupperna som kan ha betydelse för deras ställning på arbetsmarknaden. Effekten av ickeobserverbara skillnader kan därför förväxlas med diskriminering. Exempel på svenska studier där regressionsmetoden används för att undersöka diskriminering på arbetsmarknaden mot invandrare är Arai och Nekby (2007), Arai och Vilhelmsson (2004), Hammarstedt (2001, 2003), Hammarstedt och Shukur (2007), le Grand et al. (2004), Nekby (2003), Rooth (2002), Rooth och Ekberg (2003) och Vilhelmsson (2002). Troligen är också den starkt U-formade yrkesrörligheten för flyktingar som Rooth och Ekberg (2006) fann ett uttryck för diskriminering.

En tredje metod är kontrollerade laboratorieexperiment. En stor fördel med denna metod är att variabler av intresse kan kontrolleras och isoleras. Nackdelen är att miljön i ett laboratorieexperiment kan upplevas som artificiell och metoden blir mycket arbetskrävande om ett större antal observationer och individer ingår i experimentet. Hittills har metoden endast haft begränsad användning för att studera etnisk diskriminering. Metodens förmåga att kontrollera och isolera variabler av intresse gör dock att den har börjat komma till alltmer användning för den typen av studier. En klassisk undersökning är Fershtman och Gneezy (2001). För Sverige finns studier av 
exempelvis Ahmed (2007, 2009), Ahmed och Ekberg (2005) och Holm (2000).

En fjärde metod är naturliga experiment (ibland även benämnt som kvasiexperiment). Till skillnad från kontrollerade laboratorieexperiment är den oberoende variabeln i naturliga experiment inte manipulerad av forskaren utan förändringar i denna variabel uppkommer naturligt och antas vara exogena. Naturliga experiment utnyttjar alltså naturligt förekommande och observerbara fenomen och approximerar egenskaperna för kontrollerade experiment. Arai och Thoursie (2009) t.ex. studerar effekten av namnändring från ett utländskklingande till ett svenskklingande eller neutralt namn på arbetsinkomster för invandrare. Deras resultat visar att namnändring till ett svenskklingande eller neutralt namn är förknippad med en ökning av arbetsinkomster. Ett annat exempel på naturligt experiment är Åslund och Rooth (2005) som undersöker om de förändrade attityderna mot vissa invandrargrupper i Sverige efter terrorattackerna i USA den 11 september även avspeglas av en ökad diskriminering på arbetsmarknaden. Deras undersökning av utflödet från arbetslöshet till arbete runt tiden för terrorattackerna gav inget stöd för ökad diskriminering på arbetsmarknaden.

En femte metod är fältexperiment. Undersökning av diskriminering på arbetsmarknaden kan exempelvis göras genom att två identiska fiktiva jobbansökningar skickas till arbetsgivare. Skillnaden mellan ansökningarna är endast att den ena ansökan har underskrivits med ett utländskklingande namn och den andra ansökan har underskrivits med ett svenskklingande namn. Utfallsvariabeln brukar sedan oftast vara antalet jobberbjudanden eller intervjuer respektive sökande får. Till skillnad från enkätundersökningar och registerbaserade undersökningar men likhet med laboratorieexperiment observerar man i fältexperiment arbetsgivarnas faktiska beteende. Fältexperiment är till skillnad från laboratorieexperiment dessutom verklighetsförankrade och därmed mindre sterila.

Fältexperiment för att studera diskriminering har använts under många år, se t.ex. LaPiere (1934) som kanske är den första studien av dem alla. Men tekniken att använda kontrollerade fältexperiment för att mäta diskriminering på olika marknader utvecklades först för ungefär 40 år sedan av några brittiska sociologer. Daniel (1968) undersökte om det förelåg etnisk diskriminering på den brittiska arbets- och bostadsmarknaden genom att använda två matchade skådespelare som sökte jobb och lägenheter. Jowell och Prescott-Clarke (1970) utvecklade metoden genom att använda skriftliga ansökningar. Därefter har metoden även använts av nationalekonomer och med publiceringar i ledande nationalekonomiska tidskrifter som American Economic Review, Quarterly Journal of Economics och Economic Journal. Men det var inte förrän sent under året 2005 som denna metod fann sin plats i den svenska forskningen.

I november 2005 startade International Labour Office (ILO) det första fältexperimentet i Sverige för att kartlägga om det föreligger etnisk diskriminering på den svenska arbetsmarknaden, se Attström (2007). Strax efter följde några fältexperiment med samma syfte, se Arai et al. (2008), Bursell (2007), Carlsson (2008) och

Ahmed \& Ekberg: Fältexperiment för att studera.. 
Carlsson och Rooth (2007a, b). Undersökningar av diskriminering i Sverige med hjälp av fältexperiment har mestadels fokuserat på arbetsmarknaden men det finns bidrag även på bostadsmarknaden. Ahmed et al. (kommande) och Ahmed och Hammarstedt $(2007,2008$ a) har studerat om det föreligger etnisk diskriminering på bostadsmarknaden. Ahmed och Hammarstedt (2008a) har dessutom studerat om det föreligger könsdiskriminering på bostadsmarknaden. Dessutom har Ahmed et al. (2008) och Ahmed och Hammarstedt (2008b, 2009) undersökt om homosexuella personer diskrimineras på bostadsmarknaden.

Syftet med följande framställning är främst att diskutera fältexperiment som metod för att undersöka etnisk diskriminering. Vilka är metodens styrkor och svagheter? Vidare vill vi sammanfatta den forskning i Sverige som gjorts med hjälp av fältexperiment på arbets- och bostadsmarknaden. Artikeln är i fortsättningen disponerad på följande sätt: Först redogörs för fältexperiment som metod. Därefter följer ett avsnitt med en översikt av de empiriska resultaten om etnisk diskriminering på den svenska arbetsmarknaden. Dessutom summeras resultaten från motsvarande studier beträffande bostadsmarknaden. Avslutningsvis finns ett avsnitt med en framåtblickande diskussion.

\section{Fältexperiment som en metod för att studera diskriminering}

Experimentella metoder är kraftfulla för att isolera kausala samband. Traditionella experiment börjar vanligtvis med klart definierade behandlings- och kontrollgrupper till vilka deltagarna $\mathrm{i}$ experimentet slumpmässigt fördelas. Alla andra möjliga inflytanden är noggrant kontrollerade. En specifik utfallsvariabel är sedan observerad för att testa skillnader mellan grupperna. Oftast är deltagarna i ett experiment inte informerade om syftet med experimentet för att undvika bias i deras beteende.

Fältexperiment görs i en verklig omgivning till skillnad från laboratorieexperiment. Istället för att exempelvis be studenter rangordna hypotetiska jobbansökningar i ett laboratorieexperiment så presenteras i ett fältexperiment två lika kvalificerade jobbsökande för verkliga arbetsgivare.

Fältexperiment som utformas specifikt för att mäta diskriminering är antingen korrespondenstest eller situationstest. I korrespondenstest visar sig individen inte för arbetsgivaren utan endast skriftliga ansökningar skickas till utannonserade jobb. Situationstest innebär att individer antingen själv besöker arbetsgivaren eller söker jobb genom telefon. Låt oss diskutera de båda metoderna. Vi kommer att använda arbetsmarknaden som exempel. Metoderna kan självklart användas på liknande sätt för bostadsmarknaden.

\section{Korrespondenstest}

Vid korrespondenstester konstrueras två ansökningar med meritförteckningar som visar jämbördighet beträffande utbildning, erfarenhet, ålder, kön etc. Den fiktiva sökandens etnicitet är sedan signalerad genom ett eller flera sätt (vanligast genom namn). En fiktiv sökande med ett utländskklingande 
namn och en fiktiv sökande med ett svenskklingande namn tilldelas sedan slumpmässigt en av ansökningarna som skickas ut till arbetsgivare som utannonserat lediga jobb. Så den fiktiva sökande med ett utländskklingande namn använder en av ansökningarna för hälften av arbetsgivarna. På samma sätt använder den fiktive sökande med ett svenskklingande namn en av ansökningarna i hälften av fallen. Detta görs för att försäkra sig om att ickeobserverade skillnader mellan ansökningshandlingarna inte är korrelerade med de skillnader som observeras på grund av etnicitet. Turordningen för vem som söker ett jobb först hos en arbetsgivare lottas mellan de fiktiva sökande. Responsen från arbetsgivarna mäts sedan i form av antalet skriftliga svar från arbetsgivaren eller antalet svar via telefon.

De flesta korrespondenstester har utförts i Storbritannien och USA. Jowell och Prescott-Clarke (1970) var först med att använda korrespondenstest. De skickade två skriftliga ansökningar till varje utannonserat jobb i bl.a. Birmingham, Leicester och London. Den ena ansökan var alltid från en brittisk sökande medan den andra ansökan var antingen från en indisk/ pakistansk, australiensisk, cypriotisk, eller västindisk sökande. Andra exempel på brittiska studier är Esmail och Everington (1993, 1997) och Firth (1981). Samtliga studier visar att etnisk tillhörighet spelar roll för möjligheten att anställas. En ofta citerad studie som använt sig av korrespondenstest utfördes av Bertrand och Mullainathan (2004) i USA. Forskarna konstruerade två par av matchade ansökningshandlingar. Genom att använda etnisk distinkta namn för att signalera sökandes etnicitet skickade de ut ansökningar till mer än trettonhundra arbetsgivare i Chicago och Boston. De sökte alla jobb som utannonserats inom bl.a. försäljning, administration och konsumentservice. Av resultaten framgick att arbetssökande med namn som signalerade att de var vita hade 50 procent högre sannolikhet att få en positiv respons från arbetsgivaren jämfört med lika kvalificerade sökande med namn som signalerade att de var svarta. Tillvägagångssättet i undersökningen har bildat förebild för flera av de svenska studierna som diskuteras nedan.

Fördelen med korrespondenstesttekniken är att den inte kräver några riktiga jobbsökande utan endast fiktiva sökande. Detta är önskevärt både ur metodologisk och ur praktisk synpunkt. Forskaren kan skapa noggrant matchade par av sökande utan att ta hänsyn till de problem som kan uppstå med att använda riktiga personer. Således har forskaren mycket mer kontroll över de experimentella behandlings- och kontrollvillkoren. Praktiskt så underlättar fiktiva pappersansökningar logistiken av sökandeförfarandet. Istället för att koordinera och planera besök eller telefonsamtal hos arbetsgivare med riktiga sökande personer så kräver korrespondenstest endast att ansökningarna skickas ut med specificerade tidsintervall.

Även om korrespondenstest har många fördelar så finns det självklart även vissa begränsningar i tekniken. Eftersom korrespondenstest baserar sig på pappersansökningar måste all relevant information förmedlas utan visuella signaler från personlig kontakt. Forskare som vill studera etniska skillnader kan möta på svårigheter. Exempelvis kan det vara enkelt att signa-

Ahmed \& Ekberg: Fältexperiment för att studera... 
lera om en sökande är infödd svensk eller har en bakgrund från Mellan Östern men det är betydligt svårare att signalera etnicitet om man vill studera skillnader mellan olika västeuropeiska sökande. I Bertrand och Mullainthan (2004) användes etnisk distinkta namn för att signallera sökandes etnicitet. Namn som "Jamal" och "Lakisha" signalerade att den sökande var svart medan "Brad" och "Emily" associerades till vita sökande. Vissa kritiker, t.ex. Fryer och Levitt (2004), menar dock att de namn som signalerar att den sökande är svart även kan associeras till lägre socioekonomisk status vilket kan blanda ihop effekten av etnicitet och social status.

En annan begränsning med korrespondenstestmetoden kan vara karaktären på de jobb som finns tillgängliga på marknaden för studien. Den typen av ansökningsprocedur som används vid korrespondenstester det vill säga att skicka skriftliga ansökningar via posten kan vara typisk för vissa jobb. Men det finns också jobb med personliga ansökningsprocedurer. Därför har många andra studier använt sig av situationstester.

\section{Situationstest}

Vid situationstest används matchade par av individer som ger sig ut för att vara arbetssökande. Till skillnad från korrespondenstest så kontaktar individerna personligen arbetsgivaren. De sökande är noggrant matchade när det gäller utbildning, erfarenhet, ålder, kön och alla andra faktorer som kan påverka arbetsgivaren vid ett anställningsbeslut. På samma sätt som vid korrespondenstest så konstrueras ansökningshandlingar för varje sökande som reflekterar likvärdig utbildning och arbetslivserfarenhet. Utöver detta måste den personliga presentationen av de sökande vara noggrant kontrollerad. Dessutom lottas turordningen för vem av sökande som söker ett jobb först hos en arbetsgivare. De sökande måste delta i en omfattande träning för att de skall bli förtrogna med den profil de tilldelats och för att de skall lära sig att presentera sig själv för potentiella arbetsgivare i enlighet med strikt strukturerade protokoll. Dagliga utfrågningar är nödvändiga för att säkerställa att implementeringen av varje situationstest fortlöper i enlighet med planen. Situationstest är således mycket tidskrävande och kräver intensiv kontroll och bevakning.

Även om situationstester är mer tidskrävande och komplicerade så har situationstester flera fördelar jämfört med korrespondenstester. Situationstester signalerar etnicitet tydligare genom den fysiska presentationen av de arbetssökande. Förutom kvantitativa mått, som antalet arbetsgivare som svarar, så genererar situationstester även kvalitativ data, t.ex. hur en sökande blivit behandlad av arbetsgivare under en intervju.

En betydande del av fältexperimenten i Europa och USA har använt sig av situationstest. För USA se exempelvis Bendick et al. (1994), Pager (2003), Pager och Western (2005) och Turner et al. (1991). I Europa har ILO utfört situationstester i de flesta länder. Se t.ex. Arrijn et al. (1998) för Belgien, Cediey och Foroni (2007) för Frankrike och Goldberg et al. (1996) för Tyskland. Samtliga studier pekar i samma 
riktning: etnisk tillhörighet spelar roll för möjligheten att anställas. Skattningar av storleken på diskrimineringen varierar däremot kraftigt. Situationstest visar dessutom oftast på större diskriminering än korrespondenstest.

Även situationstesten har sina begränsningar. Heckman (1998) är bland dem som riktat mest kritik mot situationstester framför allt när metoden används för att studera etnisk diskriminering. Heckmans huvudsakliga kritik gäller problemet med att få två sökande likvärdiga och matchade. Situationstestets validitet väger på dess framgång med att presentera två i alla avseende lika kvalificerade arbetssökande men som skiljer sig i etnisk tillhörighet. Men givet det flertalet egenskaper som kan påverka en arbetsgivares bedömning är det oerhört svårt att försäkra att alla sådana egenskaper har blivit effektivt kontrollerade. Heckman understryker problemet med icke-observerbara egenskaper det vill säga egenskaper som inte är observerbara för forskaren men som på något sätt är synliga för potentiella arbetsgivare när de fattar sina beslut.

Ytterligare ett problem som Heckman tar upp är att matchningen (även om den görs noggrant) i sig kan leda till förvanskningar $i$ anställningsprocessen. Eftersom de sökande matchas i alla avseende som är relevanta i en anställningsprocess så kan arbetsgivare tvingas att ge vikt åt relativt mindre viktiga egenskaper för att avgöra ett oavgjort läge mellan de två sökande. Om exempelvis en arbetsgivare endast marginellt bryr sig om etnicitet men konfronteras av två $i$ andra avseenden lika arbetssökande så kan etnicitet spela en större roll i just den anställningssituationen än i normala fall då arbetssökande skiljer sig åt i flera avseende än endast etnicitet.

Det tredje argumentet mot situationstester som Heckman lyfter fram är problemet med så kallade experimenteffekter det vill säga att möjligheten att de arbetssökandes egna förväntningar och beteende kan påverka experimentets reslutat på ickeslumpmässiga sätt. Om exempelvis en arbetssökande förväntar sig att bli sämre behandlad av en arbetsgivare finns möjligheten att den sökande uppträder på ett tillbakadraget, nervöst eller defensivt sätt. Ett sådant uppträdande kan leda till en självuppfylld situation där den sökande erfar dåliga utfall. Experimenteffekter är ett allvarligt hot mot validiteten av situationstester.

Slutligen är det åter värt att påpeka att den huvudsakliga fördelen med korrespondenstester jämfört med situationstester är möjligheten att skicka matchade par av sökande med identiska ansökningshandlingar utan användning av riktiga individer. Att även korrespondenstester konsekvent visar att det föreligger diskriminering försäkrar att resultaten från situationstester inte helt beror på experimenteffekter.

\section{Rapportera och tolka resultat}

Hur skall resultaten tolkas från fältexperiment? Om diskriminering upptäcks kan oklarheter finnas beträffande omfattningen av denna. När två personer, en med ett svenskklingande namn och en med ett utländskklingande namn, söker ett jobb finns det fyra möjliga utfall: båda blir 
erbjudna ett jobb eller en intervju, endast personen med ett svenskklingande namn blir erbjuden jobbet eller intervjun, endast personen med ett utländskklingande namn blir erbjuden jobbet eller intervjun och slutligen att ingen blir erbjuden jobbet eller intervjun. Låt oss betrakta fallet då ingen får något erbjudande. Betyder en sådan observation att de sökande blivit likabehandlade eller att observationen inte ger någon information om en arbetsgivares fallenhet för att använda etnicitet som ett kriterium vid anställningsprocessen? McIntosh och Smith (1974) argumenterade för att en sådan observation skall betraktas som en icke-observation och inte som likabehandling av de sökande. Denna tolkning delas även av andra som exempelvis Brown och Gay (1985) samt Riach och Rich (1987, 1991). Andra forskare menar istället att detta får betraktas som likabehandling, se exempelvis Bendick (1996), Cross et al. (1990) och Neumark et al. (1996).

Tabell 1 belyser problematiken. Tabellen visar ett hypotetiskt exempel. Den första kolumnen (Svensk) anger antal arbetsgivare som endast kontaktade sökande med ett svenskklingande namn, den andra kolum- nen (Utländsk) anger antal arbetsgivare som endast kontaktade sökande med ett utländskklingande namn, den tredje kolumnen (Båda) anger antal arbetsgivare som kontaktade båda sökande och den fjärde kolumnen (Ingen) anger antalet arbetsgivare som kontaktade ingen av de sökande. Om observationerna då ingen blir kontaktad tolkas som icke-observationer blir nettodiskriminering lika med $(50-10) /(50+10+$ 40), dvs. 40 procent. Om observationerna då ingen blir kontaktad tolkas som likabehandling blir nettodiskrimineringen lika med $(50-10) /(50+10+40+100)$ dvs. 20 procent.

Vilket mått på nettodiskrimineringen som är korrekt att använda är svårt att säga. Däremot kan man säga att nettodiskrimineringen troligtvis ligger mellan 20 och 40 procent. Oavsett vilket mått som används är det viktigt att presentera detaljerad information som i Tabell 1.

Ett alternativt sätt att jämföra de båda sökanden är att beräkna kvoten mellan antal erbjudanden sökande med ett svenskklingande namn fått $(50+40)$ och antal erbjudanden sökande med ett utländskklingande namn fått $(10+40)$. Kvoten blir 1,8 vilket

\section{Tabell I.}

Ett hypotetiskt exempel på tolkningen av observationer

\begin{tabular}{lllllll}
\hline & Svensk & Utländsk & Båda & Ingen & ND I & ND 2 \\
\hline Respons & 50 & 10 & 40 & 100 & $40 \%$ & $20 \%$ \\
\hline
\end{tabular}

Anmärkning: I detta exempel har både personen med ett svenskklingande namn och personen med ett utländskklingande namn gjort 200 ansökningar. Svensk anger antal arbetsgivare som endast kontaktade sökande med ett svenskklingande namn, Utländsk anger antal arbetsgivare som endast kontaktade sökande med ett utländskklingande namn, Båda anger antal arbetsgivare som kontaktade båda sökande och Ingen anger antalet arbetsgivare som kontaktade ingen av de sökande. ND 1 anger nettodiskriminering om vi tolkar observationer då ingen blir kontaktad som ickeobservationer. ND 2 anger nettodiskriminering om vi tolkar observationer då ingen blir kontaktad som likabehandling. 
innebär att personen med ett svenskklingande namn kan räkna med att få 80 procent fler erbjudanden än personen med ett utländskklingande namn.

\section{Några kommentarer uretisk synpunkt}

Riach och Rich (2002, 2004) diskuterar frågan om fältexperiment är etiska eller inte. De argumenterar för att den sociala skada som diskrimineringen medför och den överlägsna precision och genomsynlighet som fältexperiment har jämfört med andra metoder rättfärdigar att man observerar arbetsgivarnas och hyresvärdarnas beteende utan att de är medvetna om det. Däremot menar Riach och Rich (2004) att vilseleda testpersoner som söker arbeten eller jobb i situationstester (dvs. att inte tala om för sina testpersoner vad syftet är med studien) inte är rättfärdigat och strider mot de flesta etiska regler. Det är dessutom onödigt då korrespondenstester kan lösa problemet.

I Sverige har vi en etikprövningslag om forskning som avser människor (SFS 2003:460). Etikprövningslagen är tydlig över vad som omfattas av lagen, dvs. vad som skall etikprövas. De regionala etikprövningsnämnderna kan även lämna rådgivande yttrande även över forskning som inte omfattas av lagen. Två forskargrupper valde att få ett rådgivande yttrande från etikprövningsnämnden. Bursell (2007) fick ett positivt yttrande från etikprövningsnämnden medan Carlsson och Rooth (2007a, b) fick svaret att fältexperiment som studerar diskriminering inte omfattas av etikprövningslagen.

\section{Resultat för den svenska arbetsmarknaden}

Det första fältexperimentet för att studera diskriminering på den svenska arbetsmarknaden utfördes av ILO på uppdrag av Integrationsverket, se Attström (2007). Detta är hittills den enda undersökning för Sverige som använder sig av situationstester, dvs. använder sig av testpersoner som utger sig att vara arbetssökande. Matchade par av testpersoner användes med en sökande med ett svenskklingande namn och en sökande med ett arabiskklingande namn. Testet använde följande steg: först ringde de sökande upp potentiella arbetsgivare, sedan skickade de sökande ut ansökningshandlingar till arbetsgivare och slutligen gick de sökande på intervju hos arbetsgivare. Det fanns således tre mått i denna studie. De är: (a) att bli inbjuden för att skicka en ansökan eller till en intervju efter ett telefonsamtal, (b) att bli inbjuden till en intervju efter en skriftlig ansökan och slutligen (c) att bli erbjuden ett jobb efter intervjun. Experimentet utfördes i Göteborg, Malmö och Stockholm och totalt sökte varje person 1431 jobb.

De andra fältexperimenten utfördes av Arai et al. (2008), Bursell (2007), Carlsson (2008) och Carlsson och Rooth (2007a, b). Korrespondenstester användes i dessa studier. Skriftliga ansökningshandlingar för fiktiva personer skickades ut till arbetsgivare i Göteborg, Malmö och Stockholm. En sökande hade ett svenskklingande namn medan den andra sökande hade ett arabiskklingande namn. För varje sökande sökte Arai et al. (2008) 566 jobb, Bursell (2007) 1776 jobb, Carlsson (2008) 1314 
jobb och Carlsson och Rooth (2007a, b) 1 552 jobb.

Samtliga fältexperiment som har utförts i Sverige har således studerat om det föreligger diskriminering av individer som har bakgrund från Mellan Östern och boende i storstadsområdena. Resultaten för de fältexperiment som utförts i Sverige sammanfattas i Tabell 2. I tabellen visas kvoten mellan antalet erbjudanden som personen med ett svenskklingande namn fick och antalet erbjudanden som personen med ett arabiskklingade namn fick.

För Attström (2007) har vi summerat resultaten i tre fall: (a) resultaten från telefonkontakten, (b) resultaten från brevkontakten och (c) resultaten från intervjun. Resultaten från telefonkontakten visar att sökande med ett svenskklingande namn fick positiva svar (inbjudan att skicka in sina ansökningshandlingar eller inbjudan till intervju) från arbetsgivaren i sex procent mer fall än sökande med ett arabiskklingande namn. Skillnaderna är betydligt större när vi betraktar brevkorrespondensen.
Sökande med ett svenskklingande namn fick mer än 2,5 gånger fler positiva svar från arbetsgivarna än sökande med ett arabiskklingande namn. Vid intervjusituationen gick det däremot bättre för sökande med ett arabiskklingande namn än sökande med ett svenskklingande namn. I detta fall är dock antalet observationer litet och skillnaden är inte statistiskt signifikant.

Carlsson och Rooth (2007a, b) visar att den fiktive sökande med ett svenskklingande namn fick ungefär 50 procent fler svar än den fiktive sökande med ett arabiskklingande namn från arbetsgivarna. Resultaten från Bursells (2007), Arai et al. (2008) och Carlsson (2008) visar på respektive 82 procent, 88 procent och 69 procent fler svar för sökande med ett svenskklingande namn.

Samtliga studier på den svenska arbetsmarknaden visar alltså att det föreligger etnisk diskriminering åtminstone av individer som har en bakgrund från Mellan Östern. På samma sätt som för USA visar de svenska studierna att diskriminering är större i situationstesten än i korrespon-

\section{Tabell 2.}

Sammanfattning av fältexperiment på arbetsmarknaden

\begin{tabular}{llrl}
\hline Studie & Metod & N & Kvot \\
\hline Arai et al. (2008) & Korrespondens & 566 & 1,88 \\
\hline Attström (2007): (a) & Situation: telefon & $\mid$ 431 & 1,06 \\
Attström (2007): (b) & Situation: brev & 1098 & 2,54 \\
Attström (2007): (c) & Situation: intervju & 44 & 0,88 \\
Bursell (2007) & Korrespondens & 1776 & 1,82 \\
Carlsson (2008) & Korrespondens & $|3| 4$ & 1,69 \\
Carlsson och Rooth $(2007 a, b)$ & Korrespondens & $\mid 552$ & 1,45 \\
\hline
\end{tabular}

Anmärkning: Kvoten har räknats ut genom att ta antalet positiva resultat erhållna för sökande med ett svenskklingande namn dividerat med antalet positiva resultat erhållna för sökande med ett arabiskklingande namn. 
denstesten åtminstone vad gäller brevkorrespondensen. Detta kan vara tecken på experimenteffekter i Attsröms (2007) studie. Det framgår av Tabell 2 att storleken på diskrimineringen även varierar något mellan korrespondenstesten. Denna variation kan bero dels på att korrespondenstesten utförts vid olika tidpunkter och dels på att det finns skillnader i experimentella designen, framför allt vad gäller i vilka yrkesområden man sökt jobben. Storleken på diskrimineringen varierar t.ex. mycket över olika yrkeskategorier (se Bursell, 2007 och Carlsson och Rooth, 2007a för en djupare diskussion om variationen av diskrimineringen över olika yrkeskategorier).

I experimenten som utfördes av Arai et al. (2008) och Carlsson (2008) laborerade forskarna även med informationen som tillhandahölls i ansökningshandlingarna. Arai et al. (2008) utförde ett korrespondenstest i två steg. I det första steget skickades till arbetsgivare likvärdiga ansökningshandlingar för en person med ett svenskklingande namn och för en person med ett arabiskklingande namn. Skillnader i antal positiva svar från arbetsgivarna observerades. I det andra steget skickades återigen ansökningshandlingar för en person med ett svenskklingande namn och för en person med ett arabiskklingande namn men i detta steg så gavs personen med ett arabiskklingande namn bättre kvalifikationer i form av större arbetslivserfarenhet. Skillnaden mellan kvinnor försvinner då kvinnan med ett arabiskklingande namn får bättre kvalifikationer. Däremot kvarstår skillnaden mellan män.

Carlsson (2008) skickade tre olika ansökningshandlingar till olika arbetsgi- vare för att studera om diskriminering av personer med arabisk härkomst beror på deras arabiskklingande namn eller på deras utländska utbildning. Carlsson (2008) skickade ut en ansökan från en person med ett svenskklingande namn, en ansökan från en person med ett arabiskklingande namn men med svensk utbildning och en ansökan från en person med ett arabiskklingande namn med utländsk utbildning. Carlsson (2008) fann att den lägre andelen positiva svar till personer med arabiskklingande namn till 23 procent kan förklaras med deras utländska utbildning och till 77 procent med deras namn.

\section{Resultat för den svenska bostadsmarknaden}

Idag finns två studier i Sverige som med hjälp av fältexperiment undersöker om det föreligger någon etnisk diskriminering på bostadsmarknaden. Både Ahmed et al. (kommande) och Ahmed och Hammarstedt (2007, 2008a) använder sig av skriftliga fiktiva ansökningar det vill säga korrespondensmetoden. Dessa studier tillsammans med Carpusor och Loges (2006) i USA är de första som använder korrespondensmetoden på bostadsmarknaden. Vad vi vet är samtliga utländska studier baserade på situationstester, se exempelvis Ondrich et al. (2003), Ondrich et al. $(1998,1999)$ och Page (1995) för USA. Förklaringen till det sistnämnda kan vara att det är ovanligt att göra skriftliga ansökningar till bostäder.

I de båda svenska studierna undersöktes skillnader beroende på om en sökande hade ett svenskklingande namn eller ett 
arabiskklingande namn. Internet, Blocket. se användes. Bostadsmarknaden är en aktiv marknad och både privata företag och privatpersoner annonserar ut lediga hyresrätter på denna hemsida. Är en bostadssökande intresserade av en viss utannonserad lägenhet på Blocket.se kan denne utan kostnad svara på annonsen genom att fylla i ett webbformulär. Den enda informationen som sökande behöver fylla i är namn, e-postadress och ett kort meddelande.

Ahmed och Hammarstedt (2008a) utförde sin studie under 2007 och Ahmed et al. (kommande) utförde sin studie under 2008. De sökte samtliga lägenheter som var utannonserade under en viss period. Svar kunde skickas till de fiktiva sökandes e-post. Om en sökande fått ett svar så noterades om hyresvärdarna avfärdade ansökan eller om de välkomnade ansökan och önskade ytterligare information. Slutligen noterades även om hyresvärdarna bjöd in de sökande direkt till en visning av lägenheten. Ahmed och Hammarstedt (2008a) sökte lägenheter hos 500 hyresvärdar medan Ahmed et al. (kommande) sökte lägenheter hos 1032 hyresvärdar. Resultaten för Ahmed et al. (kommande) har delats upp i två delar. I den första delen (a) används en ansökan som endast innehåller en intresseanmälan. I den andra delen (b) används en ansökan som innehåller information om den sökandes yrke, erfarenhet, ålder, utbildning etc. Syftet med detta var att undersöka om diskrimineringen kan elimineras genom att tillhandahålla hyresvärdarna med riklig information om de sökande. I Ahmed och Hammarstedt (2008a) används endast en ansökan som innehöll en intresseanmälan utan någon detaljerad information om den sökande. Resultaten sammanfattas i Tabell 3.

Av Ahmed och Hammarstedt (2008a) framgår att personen med ett svenskklingande namn erhöll mer än dubbelt så många positiva svar som personen med ett arabiskklingande namn. Motsvarande i Ahmeds et al. (kommande) första del (a) visar på drygt 60 procent fler positiva svar för personen med ett svenskklingande namn. I den andra delen (b), dvs. när man tillhandahåller detaljerad information om de sökande, så består diskriminering. Sökande med ett svenskklingande namn får 27 procent fler positiva svar än sökande med ett arabiskklingande namn. Jämför

\section{Tabell 3.}

Sammanfattning av fältexperiment på bostadsmarknaden

\begin{tabular}{llll}
\hline Studie & Metod & N & Kvot \\
\hline Ahmed et al. (kommande): (a) & Korrespondens & 516 & 1,61 \\
Ahmed et al. (kommande): (b) & Korrespondens & 516 & 1,27 \\
Ahmed och Hammarstedt (2008a) & Korrespondens & 500 & 2,28 \\
\hline
\end{tabular}

Anmärkning: Kvoten har räknats ut genom att ta antalet positiva resultat erhållna för sökande med ett svenskklingande namn dividerat med antalet positiva resultat erhållna för sökande med ett arabiskklingande namn. 
man resultaten för del (a) och (b) så är tendensen att diskrimineringen minskar efter att man tillfört detaljerad information om de sökande. Minskningen är dock inte statistisk signifikant. Tendensen är att det sker en minskning av diskriminering även vid jämförelse mellan studierna Ahmed och Hammarstedt (2008a) och Ahmed et al. (kommande). De sistnämna fann att diskrimineringen är densamma efter att man kontrollerat för bostadsspecifika egenskaper.

\section{En framåtblick och avslutande diskussion}

Hur kan framtida forskning förbättra skattningar och tolkningar av resultat hämtade från fältexperiment? För det första vore det en fördel om det kunde utvecklas standardiserade experiment som kan replikeras på liknande sätt som gjorts i USA, se t.ex. Turner et al. (2002). Diskriminering av olika grupper kan då studeras över tid. Effekten av politiska åtgärder för att minska diskriminering skulle lättare kunna utvärderas. För det andra har samtliga studier i Sverige valt att kartlägga diskrimineringen av personer från Mellan Östern. Det finns många andra invandrargrupper som vore intressanta undersöka. Romer har länge utpekats som en utsatt grupp. Personer med afrikansk härkomst är en annan grupp.

För det tredje har samtliga studier i Sverige, förutom Attström (2007), använt sig av korrespondenstester medan de flesta studierna i USA har använt sig av situationstester. Båda typerna av fältexperiment är viktiga och vi behöver en kombination av dessa. Situationstester visar vanligtvis på större diskriminering än korrespondenstester. Situationstester ger också mer kvalitativ information om arbetsgivarnas eller hyresvärdarnas beteende. För det fjärde bör man introducera ytterligare experimentella variabler (som utbildning, arbetslivserfarenhet, referenser, ålder osv. vilka tidigare endast fungerat som kontrollvariabler) för att kunna jämföra effekterna av etnicitet med andra nyckelfaktorer på arbets- och bostadsmarknaden. Som presenterats i denna artikel har några forskare redan gjort ett sådant försök (se Ahmed et al. kommande, Arai et al. 2008, Carlsson 2008) men mycket finns kvar att göra. Vi kan t.ex. fråga oss vad fördelen är med att ha ett svenskklingande namn jämfört med att ha en högre utbildning? Hur många fler års arbetslivserfarenhet behöver en person med ett arabiskklingande namn ha jämfört med en person med ett svenskklingande namn för att få lika många jobberbjudanden? Även om den experimentella designen och kostnader för experimentet oftast begränsar antalet variabler vore det önskevärt om framtida studier försöker laborera med andra viktiga variabler utöver etnicitet.

Det femte förslaget gäller studierna på bostadsmarknaden. Hur representativa är resultaten? Båda undersökningarna är utförda på Internet och omfattar endast privata hyresvärdar. Internet är endast en av flera sökvägar. Andra sökvägar inkluderar tidningar, kommunala bostadsbolag och sociala nätverk. Ungefär hälften av hyreslägenheterna i Sverige ägs av kommunala bolag som inte annonseras ut på samma sätt som privatägda lägenheter. För det sjätte bör framtida forskning försöka kombinera den

Ahmed \& Ekberg: Fältexperiment för att studera.. 
information som hämtas från fältexperimenten med information från enkätstudier om människors sökbeteende på arbets- och bostadsmarknaden. Detta steg är viktigt för att kunna förstå hur den funna diskrimineringen från fältexperiment står i relation till den diskriminering som människor upplever och känner själva.

Slutligen bör framtida forskning även fokusera på andra marknader än enbart arbets- och bostadsmarknaden. Diskrimineras människor t.ex. på kreditmarknaden? För många invandrare är egenföretagsamhet en möjlig väg in $i$ arbetslivet men har de samma möjligheter att få krediter som infödda? Studier från bl.a. USA visar att det finns hinder för olika etniska grupper på kreditmarknaden, se t.ex. Ladd (1998) och Ross et al. (2008). Andra studier från USA visar att det även kan förekomma dis- kriminering på olika varumarknader. Ayres (1991, 1995) och Ayres och Siegelman (1995) har undersökt diskriminering på bilmarknaden. Liknande studier för Sverige är önskvärda.

Forskning om diskriminering innehåller flera svårigheter. Även om det råder mindre samstämmighet bland forskare vad gäller vilken forskningsmetodik som är bäst för att studera diskriminering kan jämförelse mellan olika studier belysa de relativa styrkor och svagheter som olika metoder har. Denna artikel har fokuserat på de styrkor och svagheter fältexperiment har som forskningsmetod. Även om fältexperiment inte kan belysa alla relevanta sidor av diskrimineringen så genererar de ändå de mest direkta bevis på förekomsten av diskriminering.

\section{Referenser}

Ahmed, Ali M. (2007) „Group identity, social distance and intergroup bias". Journal of Economic Psychology, vol. 28, nr. 3, s. 324-337.

Ahmed, Ali M. (2009) "What is in a surname? The role of ethnicity in economic decision making". Applied Economics, under tryck.

Ahmed Ali M., Andersson Lina \& Hammarstedt Mats (2008) "Are lesbians discriminated against in the rental housing market? Evidence from a correspondence testing experiment». Journal of Housing Economics, vol. 17, nr. 3, s. 234-238.

Ahmed Ali M., Andersson Lina \& Hammarstedt Mats (kommande) "Can discrimination in the housing market be reduced by increasing the information about the applicants? «. Land Economics, vol. 86, nr. 1, under tryck.
Ahmed, Ali M. \& Ekberg, Jan (2005) „Kan kvinnliga personalchefer motverka diskriminering av invandrare». Ekonomisk Debatt, vol. 33, nr. 8, s. 72-77.

Ahmed, Ali M. \& Hammarstedt, Mats (2007) „Diskriminering på bostadsmarknaden: Effekten av att heta Mohammed". Ekonomisk Debatt, vol. 35, nr. 6, s. 34-41.

Ahmed, Ali M. \& Hammarstedt, Mats (2008a) "Discrimination in the rental housing market: A field experiment on the internet". Journal of Urban Economics, vol. 64, nr. 2, s. 362-372.

Ahmed, Ali M. \& Hammarstedt, Mats (2008b) "Diskriminering av homosexuella: Några erfarenheter från svensk ekonomisk forskning". Ekonomisk Debatt, vol. 36, nr. 8, s. 31-40.

Ahmed, Ali M. \& Hammarstedt, Mats (2009) 
"Detecting discrimination against homosexuals: Evidence from a field experiment on the Internet«. Economica, vol. 76, nr. 303, s. 588597.

Arai Mahmood, Bursell Moa \& Nekby Lena (2008) „Between meritocracy and ethnic discrimination: The gender difference». Working paper, Stockholms universitets Linnécentrum för integrationsstudier.

Arai, Mahmood \& Nekby, Lena (2007) "Gender and ethnic discrimination: An introduction". Swedish Economic Policy Review, vol. 14, nr. 1, s. 3-6.

Arai Mahmood, Regnér Håkan \& Schröder Lena (1999) $\ddot{A} r$ arbetsmarknaden öppen för alla? Stockholm: Elanders Gotab.

Arai, Mahmood, \& Skogman Thoursie, Peter (2009) "Renouncing personal names: An empirical examination of surname change and earnings". Journal of Labor Economics, vol. 27, nr. 1, s. 127-147.

Arai, Mahmood \& Vilhelmsson, Roger (2004) „Unemployment-risk differentials between immigrant and native workers in Sweden". Industrial Relations, vol. 43, nr. 3, s. 690-698.

Arrijn Peter, Feld Serge \& Nayer André (1998) Discrimination in Access to Employment on Grounds of Foreign Origin: The Case of Belgium. Genève: International Labour Office.

Attström, Karin (2007) Discrimination against Native Swedes of Immigrant Origin in Access to Employment. Genève: International Labour Office.

Ayres, Ian (1991) „Fair driving: Gender and race discrimination in retail car negotiations". Harvard Law Review, vol. 104, nr. 4, s. 817-872.

Ayres, Ian (1995) „Further evidence of discrimination in new car negotiations and estimates of its causes». Michigan Law Review, vol. 94, nr. 1, s. 109-147.

Ayres, Ian \& Siegelman, Peter (1995) "Race and gender discrimination in bargaining for a new car". American Economic Review, vol. 85, nr. 3, s. 304-321.

Bendick, Mark (1996) Discrimination against Racial/Ethnic Minorities in Access to Employ- ment in the United States: Empirical Findings from Situation Testing. Genève: International Labour Organization.

Bendick Mark, Jackson Charles W. \& Reinoso Victor A. (1994) "Measuring employment discrimination through controlled experiments". Review of Black Political Economy, vol. 23, nr. 1, s. 25-48.

Bertrand, Marianne \& Mullainathan, Sendhil (2004) "Are Emily and Greg more employable than Lakisha and Jamal? A field experiment on labor market discrimination". American Economic Review, vol. 94, nr. 4, s. 991-1013.

Brown, Colin \& Gay, Pat (1985) Racial Discrimination 17 Years After the Act. London: Policy Studies Institute.

Bursell, Moa (2007) "What's in a name? A field experiment test for the existence of ethnic discrimination in the hiring processu. Working paper, Stockholms universitets Linnécentrum för integrationsstudier.

Carlsson, Magnus (2008) »Is it your foreign name or qualifications? An experimental study of ethnic discrimination in hiringu. Working paper, Ekonomihögskolan, Växjö universitet.

Carlsson, Magnus \& Rooth, Dan-Olof (2007a) "Evidence of discrimination in the Swedish labor market using experimental dataw. Labour Economics, vol. 14, nr. 4, s. 716-729.

Carlsson, Magnus \& Rooth, Dan-Olof (2007b) „Etnisk diskriminering på svensk arbetsmarknad - resultat från ett fältexperiment». Ekonomisk Debatt, vol. 35, nr. 3, s. 55-68.

Carpusor, Adrian G. \& Loges, William E. (2006) "Rental discrimination and ethnicity in names". Journal of Applied Social Psychology, vol. 36, nr. 4, s. 934-952.

Cediey, Eric \& Foroni, Fabrice (2007) Discrimination in Access to Employment on Grounds of Foreign Origin in France. Genève: International Labour Office.

Cross Harry, Kenney Genevieve M., Mell Jane \& Zimmermann Wendy (1990) Employer Hiring Practices: Differential Treatment of Hispanic and Anglo Job Seekers. Washington: Urban Institute Press.

Ahmed \& Ekberg: Fältexperiment för att studera... 
Daniel, William W. (1968) Racial Discrimination in England. Middlesex: Penguin Books.

Esmail, Aneez \& Everington, Sam (1993) „Racial discrimination against doctors from ethnic minorities». British Medical Journal, vol. 306, nr. 13/3, s. 691-692.

Esmail, Aneez \& Everington, Sam (1997) „Asian doctors are still being discriminated against". British Medical Journal, vol. 314, nr. 31/5, s. 1619.

Fershtman, Chaim \& Gneezy, Uri (2001) „Discrimination in a segmented society: An experimental approach". Quarterly Journal of Economics, vol. 116, nr. 1, s. 351-377.

Firth, Michael (1981) "Racial discrimination in the British labor market". Industrial and Labor Relations Review, vol. 34, nr. 2, s. 265-272.

Fryer, Roland \& Levitt, Steven (2004) »The causes and consequences of distinctively black names". Quarterly Journal of Economics, vol. 119, nr. 3, s. 767-805.

Goldberg Andreas, Mourinho Dora \& Kulke Ursula (1996) Labour Market Discrimination against Foreign Workers in Germany. Genève: International Labour Office.

Hammarstedt, Mats (2001) "Disposable income differences between immigrants and natives". International Journal of Social Welfare, vol. 10, nr. 2, s. 117-126.

Hammarstedt, Mats (2003) "Income from work among immigrants in Sweden". Review of Income and Wealth, vol. 49, nr. 2, s. 185-203.

Hammarstedt, Mats \& Shukur, Ghazi (2007) "Immigrants' relative earnings in Sweden - A quantile regression approach". International Journal of Manpower, vol. 28, nr. 6, s. 456-473.

Heckman, James (1998) „Detecting discrimination". Journal of Economic Perspectives, vol. 12, nr. 2, s.101-116.

Holm, Håkan J. (2000) "What's in a name? - An ethnical discrimination experiment». Working paper, Nationalekonomiska institutionen, Lunds universitet.

Jowell, Roger \& Prescott-Clarke, Patricia (1970) „Racial discrimination and white-collar workers in Britain«. Race, vol. 11, nr. 4, s. 397-417.
Ladd, Helen F. (1998) „Evidence of discrimination in mortgage lending". Journal of Economic Perspectives, vol. 12, nr. 2, s. 41-62.

Lange, Anders (2000) Diskriminering, integration och etniska relationer. Trelleborg: Berlings Skogs $\mathrm{AB}$.

LaPiere, Richard T. (1934) "Attitudes vs. actions". Social Forces, vol. 13, nr. 2, s. 230-237.

le Grand Carl, Szulkin Ryszard \& Ekberg Jan (2004) „Kan diskriminering förklara skillnader i position på arbetsmarknaden mellan invandrare och infödda?«. I Jan Ekberg (red.) Egenförsörjning eller bidragsförsörjning? SOU 2004:21. Stockholm: Fritzes.

Mayda, Anna M. (2006) "Who is against immigration? A cross-country investigation of individual attitudes toward immigrants". Review of Economics and Statistics, vol. 88, nr. 3, s. 510530.

McIntosh, Neil \& Smith, David J. (1974) The Extent of Racial Discrimination. London: Political and Economic Planning Broadsheet.

Nekby, Lena (2003) Empirical Studies on Health Insurance, Employment of Immigrants and the Gender Wage Gap. Edsbruk: Akademitryck.

Nekby, Lena (2006) "Att mäta diskrimineringu. I Anders Neergaard (red.) På tröskeln till lönearbete: Diskriminering, exkludering och underordning av personer med utländsk bakgrund. Stockholm: Edita Sverige.

Neumark David, Ban Roy J. \& Van Nort Kyle D. (1996) "Sex discrimination in restaurant hiring: An audit study". Quarterly Journal of Economics, vol. 111, nr. 3, s. 915-941.

Ondrich Jan, Ross Stephen \& Yinge John (2003) "Now you see it, now you don't: Why do real estate agents withhold available houses from black customers?". Review of Economics and Statistics, vol. 85, nr. 4, s. 854-873.

Ondrich Jan, Stricker Alex \& Yinger John (1998) "Do real estate brokers choose to discriminate? Evidence from the 1989 housing discrimination study». Southern Economic Journal, vol. 64, nr. 4, s. 880-901.

Ondrich Jan, Stricker Alex \& Yinger John (1999) „Do landlords discriminate? The incidence and 
causes of racial discrimination in rental housing markets". Journal of Housing Economics, vol. 8, nr. 3, s. 185-204

Page, Marianne (1995) „Racial and ethnic discrimination in urban housing markets: Evidence from a recent audit study». Journal of Urban Economics, vol. 38, nr. 2, s. 183-206.

Pager, Devah (2003) „The mark of a criminal record». American Journal of Sociology, vol. 108, nr. 5, s. 937-975.

Pager, Devah \& Western, Bruce (2005) »Discrimination in low wage labor markets: Evidence from an experimental audit study in New York city". Working paper, Princeton University.

Riach, Peter A. \& Rich, Judy (1987) »Testing for sexual discrimination in the labour market". Australian Economic Papers, vol. 26, nr. 49, s. 165-178.

Riach, Peter A. \& Rich, Judy (1991) »Testing for racial discrimination in the labour market". Cambridge Journal of Economics, vol. 15, nr. 3 , s. 239-256.

Riach, Peter A. \& Rich, Judy (2002) „Field experiments of discrimination in the market place" Economic Journal, vol. 112, nr. 483, s. F480F518.

Riach, Peter A. \& Rich, Judy (2004) „Deceptive field experiments of discrimination: Are they Ethical?». Kyklos, vol. 57, nr. 3, s. 457-470.

Rooth, Dan-Olof (2002) "Adopted children in the labour market - Discrimination or unobserved characteristics?". International Migration, vol. 40, nr. 1, s. 71-98.

Rooth, Dan-Olof \& Ekberg, Jan (2003) „Unemployment and earnings for second generation immigrants in Sweden. Ethnic background and parent composition". Journal of Population Economics, vol. 16, nr. 4, s. 1432-1475.

Rooth, Dan-Olof \& Ekberg, Jan (2006) „Occupatio- nal mobility for immigrants in Sweden". International Migration, vol. 44, nr. 2, s. 57-77.

Ross Stephen L., Turner Margery A., Godfrey Erin \& Smith Robin R. (2008) "Mortgage lending in Chicago and Los Angeles: A paired testing study of the pre-application processu. Journal of Urban Economics, vol. 63, nr. 3, s. 902-919.

SFS (2003:460) Lag om etikprövning av forskning som avser människor. Svensk författningssamling.

Sheridan, Lorraine P. (2006) "Islamophobia preand post-September 11th, 2001". Journal of Interpersonal Violence, vol. 21, nr. 3, s. 317-336.

Turner Margery A., Fix Michael E. \& Struyk Raymond J. (1991) Opportunities Denied, Opportunities Diminished: Racial Discrimination in Hiring. Washington: Urban Institute Press.

Turner Margery A., Ross Stephen L., Galster Gorge C. \& Yinger John (2002) Discrimination in Met ropolitan Housing Markets: National Results from Phase 1 HDS 2000. Washington: Urban Institute Press.

Vilhelmsson, Roger (2002) Wages and Unemployment for Immigrants and Natives in Sweden. Edsbruk: Akademitryck.

Walker, Lain (1994) "Attitudes to minorities: Survey evidence of Western Australians' attitudes to Aborigines, Asians and women". Australian Journal of Psychology, vol. 46, nr. 3, s. 137-143.

Zick Andreas, Wagner Ulrich, van Dick Rolf \& Petzel Thomas (2002) "Acculturation and prejudice in Germany: Majority and minority perspectives». Journal of Social Issues, vol. 57, nr. 3 , s. 541-557.

Åslund, Olof \& Rooth, Dan-Olof (2005) "Shifts in attitudes and labor market discrimination: Swedish experiences after 9-11". Journal of Population Economics, vol. 18, nr. 4, s. 603-629.

Ahmed \& Ekberg: Fältexperiment för att studera.. 


\section{Summary}

\section{Field experiments for studying ethnic discrimination in the Swedish labour and housing markets}

During the last few years there has been an increased use of field experiment in Sweden to study ethnic discrimination in the housing and labour markets. In this article we present the methodology of field experiment, an overview of the research that has been conducted with the help of field experiments in Sweden, and some recommendations for future research. 